\title{
Design of an Analog Quasi-Steady-State Nonlinear Current-Mode Controller for Single-Phase Active Power Filter
}

\author{
Jaume Miret, Member, IEEE, Luis García de Vicuña, Miguel Castilla, \\ José Matas, and Josep M. Guerrero, Senior Member, IEEE
}

\begin{abstract}
The injection of sinusoidal current to an electrical grid is nowadays possible with the use of active power filters (APFs). With quasi-steady-state (QSS) nonlinear controllers, these power filters provide low grid-current-harmonic content with simple-control analog implementation. This paper focuses on the design of a QSS nonlinear controller for a single-phase APF. A complete analysis based on the sliding-mode-control theory is given. From the analysis, a set of control-design guidelines is presented to select the gains and parameters of the control scheme. Selected experimental results are reported to validate the theoretical design procedure.
\end{abstract}

Index Terms-Active power filter (APF), harmonics, power quality, quasi steady-state (QSS) approach.

\section{INTRODUCTION}

W ITH THE increasing use of electronic equipment, special attention has been drawn to the impact that this equipment has on ac power lines. The amount of harmonic currents flowing into the grid is growing rapidly due to polluting loads. The use of passive filters can increase power quality, but they are a costly and bulky solution. Moreover, there is no possibility of adjustment to correct harmonic currents produced by different loads.

Some power-grid-conditioning methods have been proposed in the literature to minimize harmonic distortion currents and to correct the power factor on the electric network [1]-[6]. One of the most popular power-grid conditioners is the active power filter (APF), with shunt connection [3]-[14] or series connection with the load [15]. Several topologies are possible, including full-bridge voltage source inverter and full-bridge current source inverter [16].

The main purpose of the shunt APF system is to supply the harmonics absorbed by the nonlinear load, in order to provide the grid current with a low harmonic content. To this end,

Manuscript received September 25, 2008; revised June 15, 2009. First published July 7, 2009; current version published November 6, 2009. This work was supported by the Spanish Ministry of Science and Technology under Grant ENE2006-15521-C03-01.

J. Miret, L. García de Vicuña, M. Castilla, and J. Matas are with the Department of Electronic Engineering, Technical University of Catalonia, 08800 Vilanova i la Geltrú, Spain (e-mail: jmiret@eel.upc.edu; vicuna@eel.upc.edu; mcastilla@eel.upc.edu; matasalc@gmail.com).

J. M. Guerrero is with the Department of Automatic Control Systems and Computer Engineering, Technical University of Catalonia, 08036 Barcelona, Spain (e-mail: josep.m.guerrero@upc.edu).

Digital Object Identifier 10.1109/TIE.2009.2026385 the control of APF systems has been widely studied in the literature. The basic approach consists of two control loops. The outer voltage loop is responsible for capacitor-voltage regulation while the inner current loop performs the referencecurrent-signal tracking. For the reference-signal generation, a direct method consists of sensing the load current and extracting the harmonic content. Then the filter current is used in the inner current loop to track the load-current harmonics [7], [11]. As an alternative, an indirect method generates a sinusoidal reference signal by means of grid-voltage sensing. In that case, the grid current is forced to follow this sinusoidal signal and, thus, the load harmonics are indirectly given by the APF inductor current [8], [17]. The main advantages of this second approach are that only one low-bandwidth current sensor is required and faster transient response is obtained [17], [18].

To improve the performance of the basic approaches, different control solutions have been proposed. Recent works have proposed digital implementations with time or frequencydomain mathematical representations [18]-[26]. These control solutions give high performance and flexible designs. However, fast digital signal processors are required to compute the complex mathematical calculations, yielding costly schemes.

Analog-control implementations have also been widely evaluated in the literature [7]-[12]. The conventional control configuration provides good performance at nominal grid conditions. However, in distorted grids, additional analog circuitry should be necessary to maintain the expected features. To simplify the control circuitry, the quasi steady-state (QSS) approach has been successfully applied to switching converters and particularly to shunt APFs [27]-[29]. The basic implementation uses an integrator with a reset signal which is synchronized with each switching cycle, in order to compute the duty ratio. The method is simple, but it loses the advantages of past behavior in error correction caused by the integrator periodic reset [30]. An improved QSS controller has been recently presented in [31]. This control scheme has superior performance characteristics due to its ability to maintain the past behavior of the system. This feature is achieved through the use of an analog multiplexer and a bandpass filter instead of the reset integrator.

In this paper, we present a complete design-oriented study for the QSS nonlinear controller reported in [31]. The analysis is based on the sliding-mode-control theory. A set of design guidelines for the selection of the gain and parameters of the 


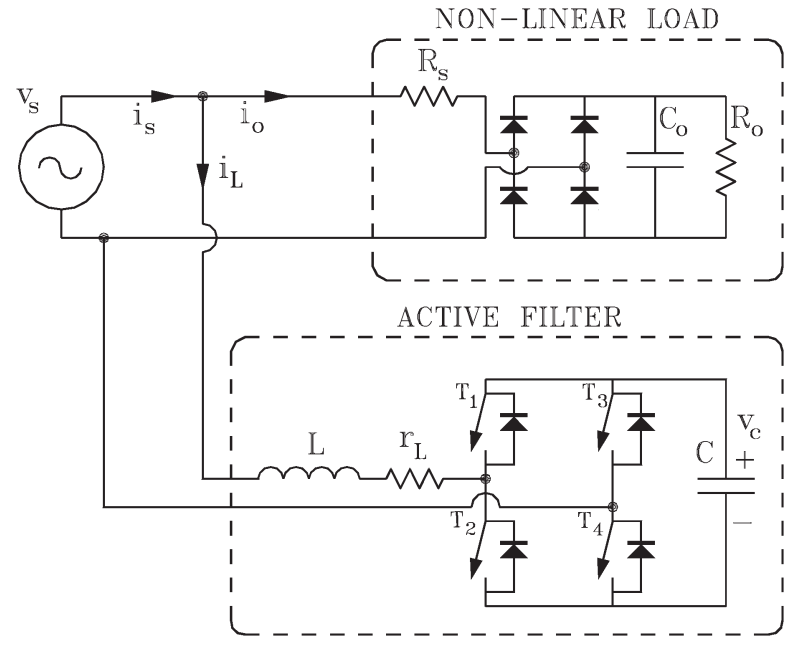

Fig. 1. Shunt active power filter.

TABLE I

STATE OF SWITCHES AND CONTROL INPUT $u$

\begin{tabular}{ccccc}
\hline \hline$T_{1}$ & $T_{4}$ & $T_{2}$ & $T_{3}$ & $u$ \\
\hline on & on & off & off & 1 \\
off & off & on & on & -1 \\
\hline
\end{tabular}

QSS controller is identified by means of the evaluation of existence, reaching, and stability conditions. In addition, the effect of the bandpass-filter characteristics on the APF performance is analyzed. As a result, we propose a systematic procedure for the design of the QSS controller. This procedure constitutes the main contribution of this paper.

This paper is organized as follows. Section II reviews the analog-control implementations for the shunt APF. Section III uses the sliding-mode-control theory to devise the QSS nonlinear control configuration. Section IV presents some controldesign guidelines. Section V corroborates the expected features of the proposed controller by means of selected experimental results. Also, a performance comparison with a reference APF controller is provided. Section VI presents the conclusion.

\section{CONVEnTIONAL InDiRECT CONTROL FOR Single-Phase SHUNT APF}

Fig. 1 shows a typical configuration of a full-bridge APF circuit in parallel with both the grid and the nonlinear load. For the APF control, we adopt the basic bipolar modulation scheme due to its easy analog implementation. Table I sums up the state of the switches and the definition of the control input $u$ for this modulation technique.

From Table I, the dynamic model of the APF circuit can be easily expressed as

$$
\begin{aligned}
\frac{d i_{L}}{d t} & =\frac{1}{L}\left(v_{s}-r_{L} \cdot i_{L}-v_{c} \cdot u\right) \\
\frac{d v_{c}}{d t} & =\frac{i_{L}}{C} \cdot u .
\end{aligned}
$$

Normally, the grid frequency is well below the switching frequency. Therefore, the variables of the aforementioned model can be considered nearly constant in one switching period.
Following this QSS approach [27]-[29], the relationship between voltages $v_{c}$ and $v_{s}$ can be expressed as

$$
\frac{v_{c}}{v_{s}} \approx \frac{1}{\langle u\rangle}
$$

where $\langle u\rangle$ is the average value of the control variable $u$ over one switching period. This simple expression will be used next to derive the nonlinear control proposed in this paper.

Fig. 2 shows the control configuration for the shunt APF circuit [10]. It consists of two control loops and a modulation scheme. The inner current loop is responsible for assuring that the grid current $i_{s}$ remains sinusoidal and in phase with the grid voltage $v_{s}$. This control objective can be expressed as

$$
i_{s}=i_{s}^{*}=k \cdot v_{s}
$$

where $i_{s}^{*}$ is the reference current, and $k$ is a slow-varying variable which accounts for the average power consumed by the nonlinear load. Note that an analog multiplier is required for the implementation of this control objective.

The value of $k$ is given by an outer voltage loop, usually by means of a proportional-integral (PI) compensator of the voltage error $e_{v}=v_{c}^{*}-v_{c}$. In common practice, the voltage $v_{c}$ is filtered out through a low-pass filter with a cutoff frequency less than twice the grid frequency, in order to reduce the harmonic content of both the variable $k$ and the reference current [8].

The last stage of the conventional indirect controller includes the modulation scheme. From an analog implementation point of view, an interesting sliding-mode modulation technique is given in [8]. A simple sliding surface is defined using the gridcurrent error

$$
s=i_{s}-i_{s}^{*} .
$$

The control law, which forces the grid current to track the reference signal, can be expressed as [8]

$$
u= \begin{cases}1, & \text { for } s>0 \\ -1, & \text { for } s<0 .\end{cases}
$$

Normally, a high-bandwidth current compensator is necessary in a conventional pulsewidth modulation scheme. Following this sliding-mode approach, the compensator of the inner current loop is not required.

The indirect sliding-mode control described here will be used as a reference control in the experimental performance comparison provided in Section V.

\section{QSS SLIDING-Mode CONTROLleR}

The aim of this section is to derive a QSS sliding-mode controller which avoids the use of an analog multiplier in the outer voltage loop. Some details about the practical implementation of the proposed controller are also presented.

\section{A. Derivation of Control Configuration}

The QSS approach is considered here to obtain the output of the outer voltage loop $i_{s}^{*}$. It is important to note that in steady 


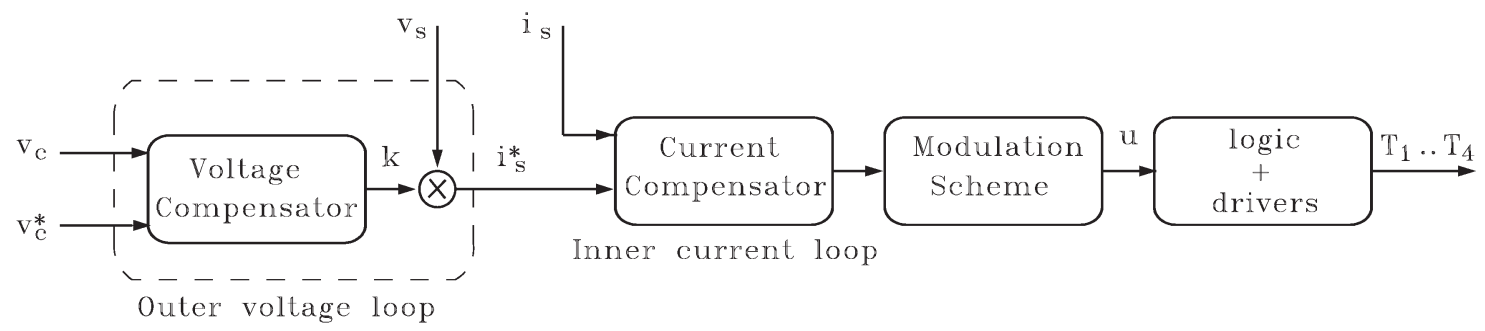

Fig. 2. Conventional indirect control for the single-phase APF circuit.

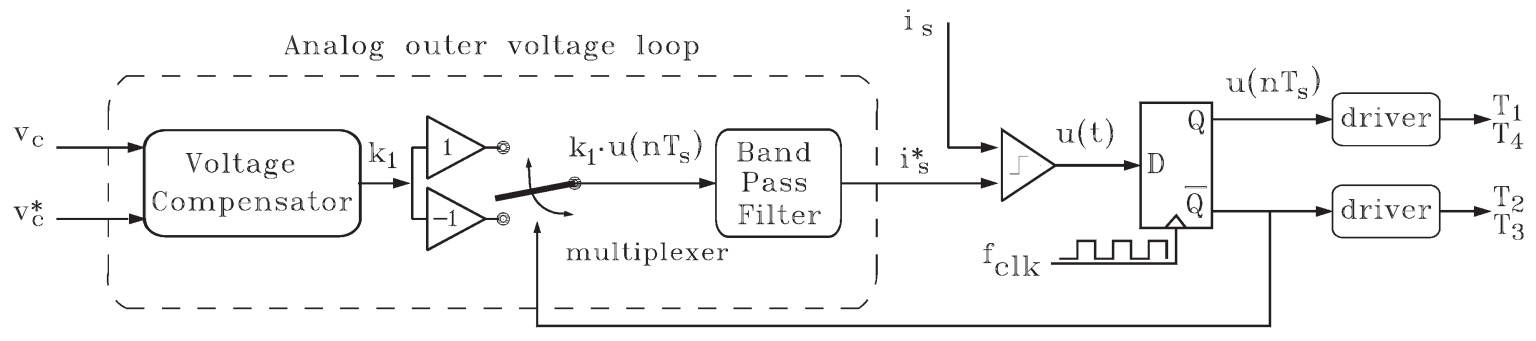

Fig. 3. Proposed QSS sliding-mode controller.

state, $\langle u\rangle$ is a nearly sinusoidal waveform, and the variables $k$ and $v_{c}$ are slow-varying signals with respect to the switching period. Substituting (3) into (4), the main control objective can be alternatively expressed as

$$
i_{s} \approx k \cdot v_{c} \cdot\langle u\rangle=k_{1} \cdot\langle u\rangle
$$

where $k_{1}$ is the output of the PI compensator of the error voltage $e_{v}$, i.e.,

$$
k_{1}=k_{p}\left(v_{c}^{*}-v_{c}\right)+k_{i} \int\left(v_{c}^{*}-v_{c}\right) d t .
$$

Note that (7) gives the desired control objectives without sensing the grid voltage, but an analog multiplier is still required.

Because $k_{1}$ is almost constant and a slow-varying signal, a second approximation can be made; $k_{1} \cdot\langle u\rangle \approx\left\langle k_{1} \cdot u\right\rangle$, that is, the product of two analog signals $\left(k_{1}\right.$ and $\left.\langle u\rangle\right)$ is replaced by the average value of the product of an analog signal $\left(k_{1}\right)$ and a discrete one $(u)$. In that case, a bandpass filter and a multiplexer can be used to implement the reference current $\left\langle k_{1} \cdot u\right\rangle$ [31], eliminating the need for an analog multiplier in the outer voltage loop

$$
i_{s}=i_{s}^{*}=\left\langle k_{1} \cdot u\right\rangle .
$$

The bandpass filter used to obtain $\left\langle k_{1} \cdot u\right\rangle$ must be tuned to the grid frequency to reject all the current harmonics except the fundamental one.

\section{B. Controller Implementation}

Fig. 3 shows the implementation of the control objective (9) following a sliding-mode-control approach. The sliding surface is easily derived by identifying (9) with the well-known existence condition $s=0$

$$
s=i_{s}-i_{s}^{*}=i_{s}-\left\langle k_{1} \cdot u\right\rangle .
$$

The characteristics of the bandpass filter have a significant effect on the APF performance. The bandwidth should be small enough to sufficiently attenuate the harmonic components of the reference current. However, a slow transient response with an important delay is obtained with a narrow bandpass filter. In Section V, a solution for this design tradeoff is given for the proposed controller.

In addition, the sensing of the grid voltage is not necessary in the proposed controller, given that the reference current produces a sinusoidal waveform by means of the averaged value of the control variable $u$, as shown in (3). In that case, the gridvoltage harmonics do not affect the generation of the reference thus reducing the grid-current total harmonic distortion (THD). This is an interesting property for an APF circuit, particularly under distorted grid condition.

With the proposed controller, the switching frequency varies during the grid period, due to the inherent behavior of the sliding-mode control. The maximum frequency is expected at zero-voltage crossing points and the minimum frequency is obtained at peak grid-voltage values. In the proposed controller, the maximum switching frequency $f_{s, \max }$ is fixed by using a D flip-flop at the output of the comparator. A clock generator oscillating at $f_{\mathrm{clk}}$ forces that $f_{s, \max }=f_{\text {clk }} / 2$. The complementary outputs of the flip-flop, $u\left(n T_{s}\right)$ and $\bar{u}\left(n T_{s}\right)$, drive the power switches. The signal $u\left(n T_{s}\right)$ indicates the sampled value of the variable $u(t)$ at the frequency $f_{s, \max }\left(T_{s}=1 / f_{s, \max }\right)$.

Fig. 4 shows a possible implementation of the multiplexer based on two bipolar transistors. The output of the circuit is the voltage $k_{1} \cdot u\left(n T_{s}\right)$.

\section{Design of Proposed Controller}

This section presents some guidelines for the design of the proposed controller. The design is based on the sliding-modecontrol theory. In particular, reaching, existence, and stability conditions will be examined. 


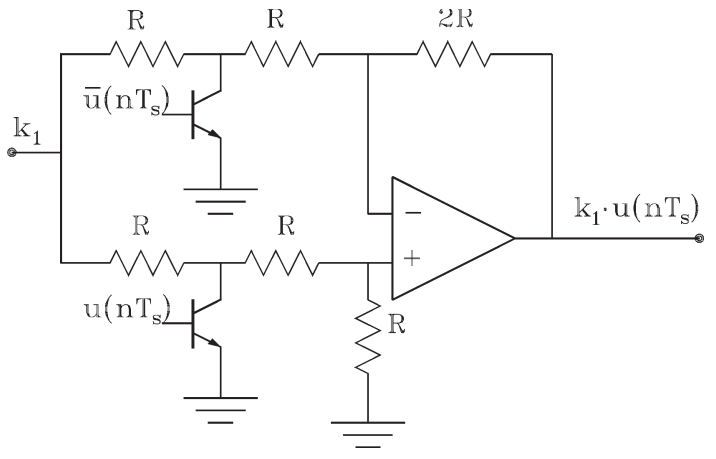

Fig. 4. Analog implementation of $k_{1} \cdot u\left(n T_{s}\right)$.

\section{A. Reaching Condition}

In a sliding-mode-control system, the fulfillment of the reaching condition ensures that, regardless of the initial system state, the state trajectory of the system will always be directed toward the sliding surface. The direction of these state trajectories is governed by the control law

$$
u= \begin{cases}u^{+}, & \text {for } s>0 \\ u^{-}, & \text {for } s<0\end{cases}
$$

where $u^{+}$and $u^{-}$can take the values 1 or -1 in the current application.

The design of $u^{+}$and $u^{-}$is carried out normally by using the well-known local reaching condition [32], [33]

$$
\lim _{s \rightarrow 0} s \cdot \frac{d s}{d t}<0 .
$$

Using (1), (2), and (9), it is easy to derive that $u^{+}=1$ and $u^{-}=-1$ guarantee the accomplishment of (12).

\section{B. Existence Condition}

In a sliding-mode-control system, the reaching regime is finished when the system state reaches the sliding surface and stays on it. In that case, the sliding regime appears and is characterized by a particular system dynamics restricted over the sliding surface. In order for the sliding motion to exist, the following conditions must be observed [34]:

$$
s=0 \quad \frac{d s}{d t}=0 .
$$

Theoretically, the equivalent control $u_{\mathrm{eq}}$ is a continuous control input that satisfies (13). By substituting (8) and (10) in (13), the equivalent control can be expressed as

$$
u_{\mathrm{eq}}=\frac{\left\langle i_{s}\right\rangle}{k_{1}}=\frac{\left\langle i_{s}\right\rangle}{k_{p}\left(v_{c}^{*}-\left\langle v_{c}\right\rangle\right)+\left\langle i_{i}\right\rangle}
$$

where $\left\langle i_{s}\right\rangle$ and $\left\langle i_{i}\right\rangle$ are the average values of $i_{s}$ and $i_{i}$ respectively, over one switching period. Note that $\left\langle i_{i}\right\rangle$ is a state variable introduced by the integral term of the PI compensator

$$
\frac{d\left\langle i_{i}\right\rangle}{d t}=k_{i}\left(v_{c}^{*}-\left\langle v_{c}\right\rangle\right)
$$

It is worth mentioning that the equivalent control input expressed in (14) exists, and, thus, a sliding motion is possible over the sliding surface defined in (10).

\section{Attraction Domain}

A design condition for the reference voltage is derived here using the attraction-domain analysis.

By inserting (14) in (1) and (2), the low-frequency dynamics of the APF circuit can be written as

$$
\begin{aligned}
& \frac{d\left\langle i_{L}\right\rangle}{d t}=\frac{1}{L}\left(\left\langle v_{s}\right\rangle-\left\langle i_{s}-i_{o}\right\rangle \cdot r_{L}-\frac{\left\langle v_{c}\right\rangle \cdot\left\langle i_{s}\right\rangle}{k_{p}\left(v_{c}^{*}-\left\langle v_{c}\right\rangle\right)+\left\langle i_{i}\right\rangle}\right) \\
& \frac{d\left\langle v_{c}\right\rangle}{d t}=\frac{1}{C}\left(\frac{\left\langle i_{s}-i_{o}\right\rangle \cdot\left\langle i_{s}\right\rangle}{k_{p}\left(v_{c}^{*}-\left\langle v_{c}\right\rangle\right)+\left\langle i_{i}\right\rangle}\right) .
\end{aligned}
$$

Note that the closed-loop system dynamics is represented by the nonlinear model (15)-(17).

It is well known that the control variable $u_{\text {eq }}$ must be restricted to the maximum and minimum values of the control input variable $u$ [34]. Given that $u_{\max }=1$ and $u_{\min }=-1$, the attraction-domain restriction is expressed as

$$
-1<\frac{\left\langle v_{s}\right\rangle-L \cdot \frac{d\left\langle i_{L}\right\rangle}{d t}}{\left\langle v_{c}\right\rangle}<1 .
$$

This condition must be observed to avoid the saturation of the control. A design condition can be formulated for the parameter $v_{c}^{*}$ considering the worst possible scenario, i.e., the variables of (18) have their maximum values

$$
v_{c}^{*}>\left|\left\langle v_{s}\right\rangle\right|_{\max }+L \cdot\left|\frac{d\left\langle i_{L}\right\rangle}{d t}\right|_{\max } .
$$

In the particular case that the grid is supplying a nonlinear load with a high crest factor, the maximum slew rate of the load current limits the system performance. Then, taking into account that

$$
\left|\frac{d\left\langle i_{o}\right\rangle}{d t}\right|_{\max }>\left|\frac{d\left\langle i_{s}\right\rangle}{d t}\right|_{\max }
$$

the previous design condition can be formulated as

$$
v_{c}^{*}>\left|\left\langle v_{s}\right\rangle\right|_{\max }+L \cdot\left|\frac{d\left\langle i_{o}\right\rangle}{d t}\right|_{\max } .
$$

It is interesting to note that the required reference voltage is normally higher in the APF system in comparison with other applications using a step-up-based converter topology (such as high-power-factor boost preregulators and dc/dc boost regulators). In such applications, the maximum value of the load-current time derivate is normally negligible, which does not happen in the case of the APF system.

\section{Stability Condition}

In a sliding-mode-control system, the fulfillment of the stability condition ensures that the state trajectory of the system will always reach a stable equilibrium state. As stated previously, the low-frequency dynamics of the APF system is 
expressed in (15)-(17) by a nonlinear description. The system stability is then examined using a small-signal model. Usually, the small-signal model of the APF system considers only the dynamics of the capacitor voltage [7]. In this section, the whole nonlinear-model description is used in the small-signal-model derivation to obtain a complete set of design conditions.

The variables of the nonlinear model (15)-(17) contain, in general, dc and ac components. For the control design, only the ac components with frequencies below the grid frequency have significant information. These components can be extracted by averaging the nonlinear model over one-half grid period [35], [36]. Thus, all the variables in the system model can be represented as quiescent-averaged values plus their smallsignal variations. Note that the small-signal variables have nonsinusoidal waveforms due to the low-frequency averaging process. The averaged variables can be expressed as

$$
\begin{aligned}
\bar{i}_{L} & =I_{L}+\hat{i}_{L}(t) \\
\bar{v}_{c} & =V_{c}+\hat{v}_{c}(t) \\
\bar{i}_{i} & =I_{i}+\hat{i}_{i}(t) \\
\bar{v}_{s} & =V_{s}+\hat{v}_{s}(t) \\
\bar{i}_{s} & =I_{s}+\hat{i}_{s}(t) \\
\bar{i}_{o} & =I_{o}+\hat{i}_{o}(t) \\
\bar{i}_{o 1} & =I_{o 1}+\hat{i}_{o 1}(t) .
\end{aligned}
$$

Note that two load currents are defined in (27) and (28). The first one $\bar{i}_{o}$ is the current absorbed by the nonlinear load. The second one $\bar{i}_{o 1}$ is the first-harmonic component of $\bar{i}_{o}$. The current $\bar{i}_{o 1}$ is introduced in the model by the averaging process of the product $\left\langle i_{s}-i_{o}\right\rangle \cdot\left\langle i_{s}\right\rangle$ expressed in (17). It should be mentioned that the averaging of the product of a sinusoidal signal $\left\langle i_{s}\right\rangle$ and a signal with a rich-harmonic content $\left\langle i_{s}-i_{o}\right\rangle$ yields values that are different from zero only at the firstharmonic component (property of orthogonality).

By substituting (22)-(28) into (15)-(17) and averaging over one-half grid period, a model with quiescent and small ac variation variables is obtained

$$
\begin{aligned}
& \frac{d\left(I_{s}+\hat{i}_{s}(t)\right)}{d t} L-\frac{d\left(I_{o}+\hat{i}_{o}(t)\right)}{d t} L \\
& =V_{s}+\hat{v}_{s}(t)-r_{L} \cdot\left(I_{s}+\hat{i}_{s}(t)-I_{o}-\hat{i}_{o}(t)\right) \\
& \quad-\frac{\left(V_{c}-\hat{v}_{c}(t)\right) \cdot\left(I_{s}+\hat{i}_{s}(t)\right)}{k_{p}\left(v_{c}^{*}-V_{c}-\hat{v}_{c}(t)\right)+I_{i}+\hat{i}_{i}(t)} \\
& \frac{d\left(V_{c}+\hat{v}_{c}(t)\right)}{d t} \\
& =\frac{\pi^{2}}{8 C}\left(\frac{\left(I_{s}+\hat{i}_{s}(t)\right) \cdot\left(I_{s}+\hat{i}_{s}(t)-I_{o 1}-\hat{i}_{o 1}(t)\right)}{k_{p}\left(v_{c}^{*}-V_{c}-\hat{v}_{c}(t)\right)+I_{i}+\hat{i}_{i}(t)}\right) \\
& \begin{array}{l}
d\left(I_{i}+\hat{i}_{i}(t)\right) \\
d t
\end{array} \quad k_{i}\left(v_{c}^{*}-V_{c}-\hat{v}_{c}(t)\right) .
\end{aligned}
$$

TABLE II

PARAMETER VAlues of APF Circuit for EXPerimental Test

\begin{tabular}{lll}
\hline \hline Grid voltage & $v_{s, r m s}$ & $110 \mathrm{~V}, 60 \mathrm{~Hz}$ \\
\hline Nominal Power & $S$ & $600 \mathrm{VA}$ \\
\hline Filter inductance & $L$ & $5 \mathrm{mH}$ \\
\hline Filter parasitic resistance & $r_{L}$ & $0.34 \Omega$ \\
\hline Filter capacitor & $C$ & $1.5 \mathrm{mF}$ \\
\hline Load parameters & $R_{s}$ & $4 \Omega$ \\
& $R_{o}$ & $45 \Omega$ \\
\hline Nominal load current & $C_{o}$ & $500 \mu \mathrm{F}$ \\
\hline Nominal first harmonic load current & $i_{o, r m s}$ & $4 \mathrm{~A}$ \\
\hline$v_{c}$ RC low-pass filter & $f_{c}$ & $3.2 \mathrm{~A}, 60 \mathrm{~Hz}$ \\
\hline PI voltage control & $k_{i}$ & $40 \mathrm{~Hz}$ \\
\hline & $k_{p}$ & $0.64 \mathrm{~A} / \mathrm{V}$ \\
\hline$k_{l} \cdot u$ second-order band-pass filter & $v_{c}{ }^{*}$ & $200 \mathrm{~V}$ \\
\hline Maximum switching frequency & $B W$ & $60 \mathrm{~Hz}$ \\
\hline \hline
\end{tabular}

Taking the quiescent values separately, the following steadystate relationships are deduced:

$$
I_{i}=\frac{V_{c} \cdot I_{s}}{V_{s}+r_{L} \cdot\left(I_{o}-I_{s}\right)}=\frac{v_{c}^{*} \cdot i_{o 1, \mathrm{rms}}}{v_{s, \mathrm{rms}}+r_{L} \cdot\left(i_{o, \mathrm{rms}}-i_{o 1, \mathrm{rms}}\right)}
$$

$I_{s}=I_{o 1}=\frac{2 \cdot \sqrt{2}}{\pi} i_{o 1, \mathrm{rms}}$

$V_{c}=v_{c}^{*}$

where $v_{s, \mathrm{rms}}$ and $i_{o 1, \mathrm{rms}}$ are the rms values of the grid voltage and load-current first harmonic, respectively (see Table II).

The small-signal closed-loop model of the variable $\hat{v}_{c}$ is, finally, derived by inserting (32)-(34) into (29)-(31) and disregarding the second-order ac terms. In the Laplace domain, the model can be expressed as

$$
\left(s^{3}+a_{2} s^{2}+a_{1} s+a_{0}\right) \hat{v}_{c}(s)=f\left(\hat{v}_{s}(s), \hat{i}_{o}(s), \hat{i}_{o 1}(s)\right)
$$

where

$$
\begin{aligned}
& a_{2}=\frac{v_{c}^{*}+I_{i} \cdot r_{L}}{I_{i} \cdot L} \\
& a_{1}=\frac{i_{o 1, \mathrm{rms}}}{C L \cdot I_{i}^{2}}\left(i_{o 1, \mathrm{rms}}+k_{p}\left(v_{s, \mathrm{rms}}+r_{L}\left(i_{o, \mathrm{rms}}-i_{o 1, \mathrm{rms}}\right)\right)\right) \\
& a_{0}=\frac{k_{i} \cdot i_{o 1, \mathrm{rms}}}{C L \cdot I_{i}^{2}}\left(v_{s, \mathrm{rms}}+r_{L}\left(i_{o, \mathrm{rms}}-i_{o 1, \mathrm{rms}}\right)\right)
\end{aligned}
$$

With the linear model (35) in mind, the stability analysis is performed using the well-known Routh's-Hurwitz criterion. 


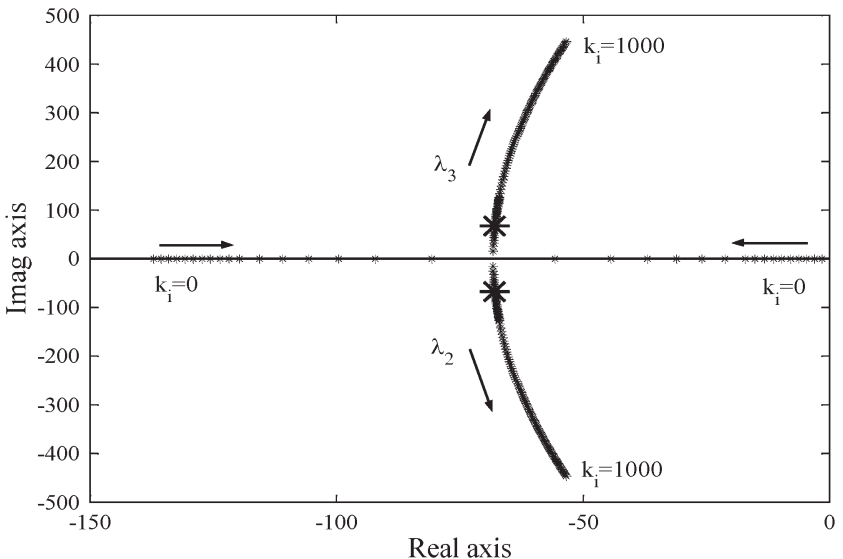

(a)

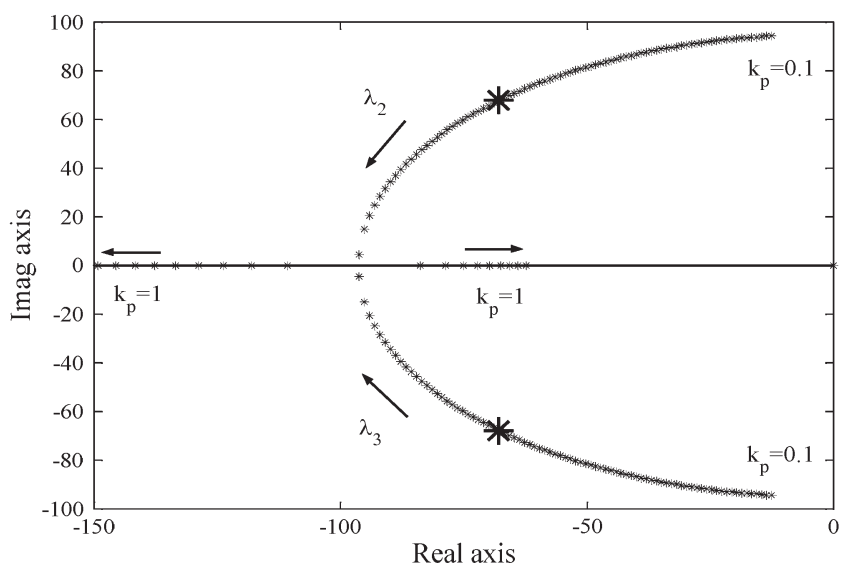

(b)

Fig. 5. Family of root-locus diagram. (a) $k_{p}=0.64$ for $0<k_{i}<1000$. (b) $k_{i}=45$ for $0.1<k_{p}<1$. Chosen locations for poles $\lambda_{2}$ and $\lambda_{3}$ are indicated by the large asterisks.

The stability limits of the gain parameters of the PI compensator can be expressed as the following stability condition:

$$
\begin{aligned}
k_{p} & >-\frac{i_{o 1, \mathrm{rms}}}{v_{s, \mathrm{rms}}+r_{L}\left(i_{o, \mathrm{rms}}-i_{o 1, \mathrm{rms}}\right)} \\
0< & k_{i} \\
& <\frac{\left(v_{c}^{*}+I_{i} \cdot r_{L}\right) \cdot\left(i_{o, \mathrm{rms}}+k_{p}\left(v_{s, \mathrm{rms}}+r_{L}\left(i_{o, \mathrm{rms}}-i_{o 1, \mathrm{rms}}\right)\right)\right)}{I_{i} \cdot L \cdot\left(v_{s, \mathrm{rms}}+r_{L}\left(i_{o, \mathrm{rms}}-i_{o 1, \mathrm{rms}}\right)\right)} .
\end{aligned}
$$

An analysis of (35) through the representation of some rootlocus diagrams gives additional information about the transient response of the system. Using the values shown in Table II, we observe that a negligible high-frequency real pole exists $\left(\lambda_{1}\right.$ at $\left.-6.7 \cdot 10^{30} \mathrm{rad} / \mathrm{s}\right)$. Besides, neither $k_{p}$ nor $k_{i}$ have any noticeable effects on this pole location.

Fig. 5 shows the root-locus diagram of the two remainder poles, $\lambda_{2}$ and $\lambda_{3}$, under different values of the $k_{p}$ and $k_{i}$ coefficients. The high-frequency pole $\lambda_{1}$ is omitted in this figure. Note that there is a wide range of possible pole locations, so the desired transient response can be easily satisfied. In common practice, the bandwidth of the outer voltage loop must be sufficiently low to avoid an undesired harmonic content in the grid current. Therefore, the PI compensator gains are set at
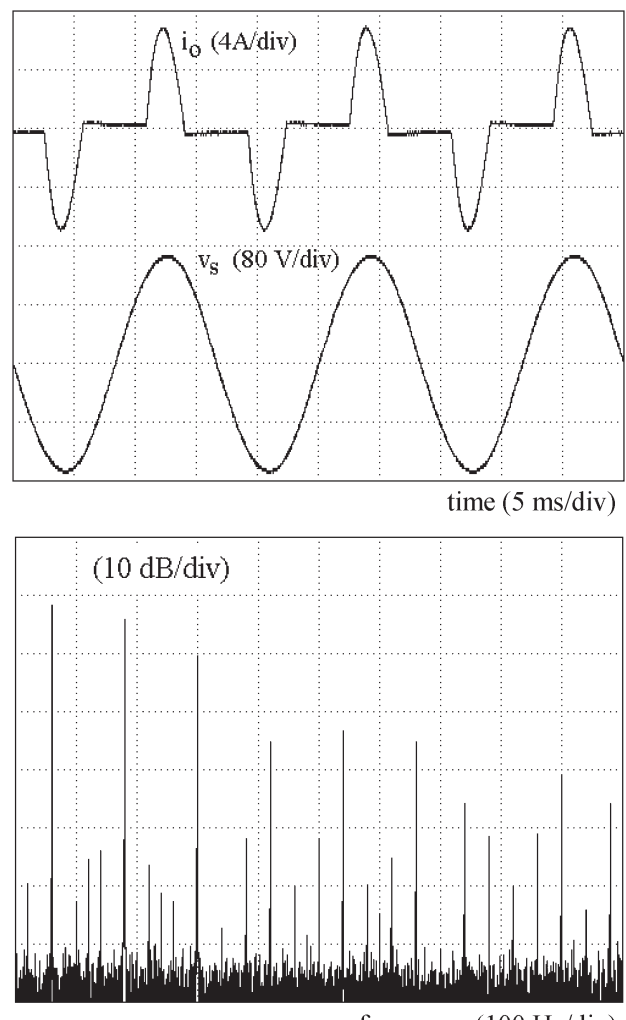

frequency $(100 \mathrm{~Hz} /$ div $)$

Fig. 6. (Top) Load current and grid voltage, and (bottom) load-current spectrum with the nondistorted grid feeding an uncontrolled bridge rectifier.

$k_{p}=0.64$ and $k_{i}=45$ to achieve an equivalent second-order dynamics with a damping factor of $\xi=0.707$ and a natural frequency of $\omega_{n}=2 \pi \cdot 15.2 \mathrm{rad} / \mathrm{s}$.

\section{EXPERIMENTAL RESUlts}

In this section, experimental results are provided to validate the proposed control. A comparison with a reference controller is also given.

\section{A. Experimental Setup}

An experimental prototype of the active filter was built using four insulated-gate bipolar transistor (IGBT) switches from a Mitsubishi PM50RSK60 intelligent power module. Table II lists the parameter values of both the APF circuit and the proposed controller. The maximum switching frequency is $18 \mathrm{kHz}$ according to the limits expected for the IGBT switching characteristics. The power components have been designed using the guidelines reported in [8]. The design of the PI gain coefficients was presented in the previous section. The remainder-control parameters have been experimentally selected according to the following criteria.

1) The value for $v_{c}^{*}$ must fulfill the design condition (21).

2) The cutoff frequency of the $v_{c}$ low-pass filter must be set at less than twice the grid frequency, to reduce the harmonic content of the reference current.

3) The bandpass-filter parameters must be selected according to the need to attenuate all the undesired current harmonics and to guarantee a fast enough transient 


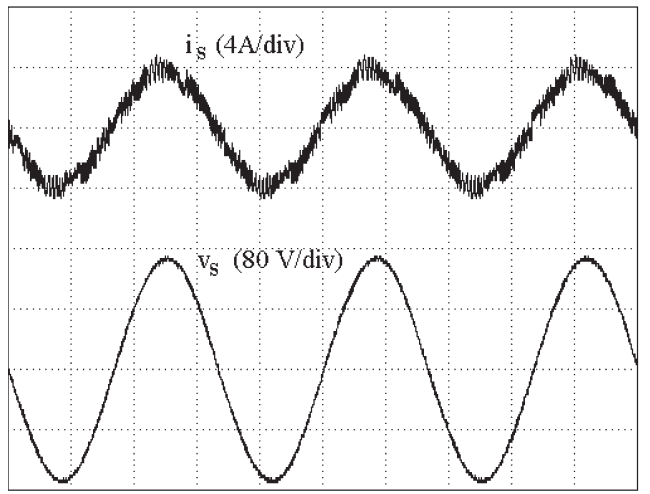

time $(5 \mathrm{~ms} / \mathrm{div})$

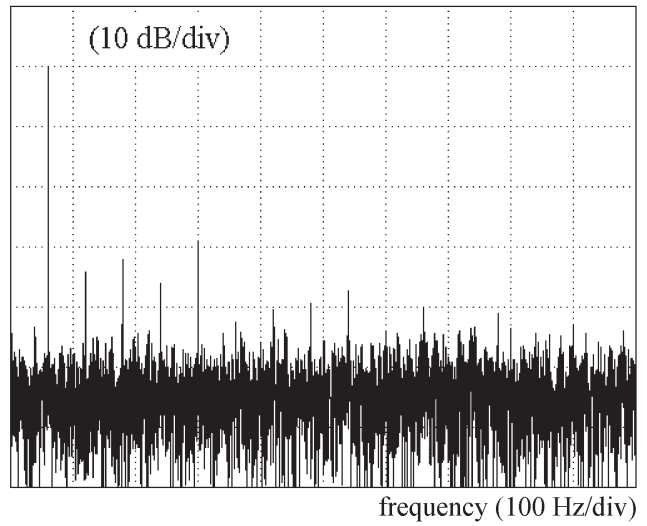

reference control
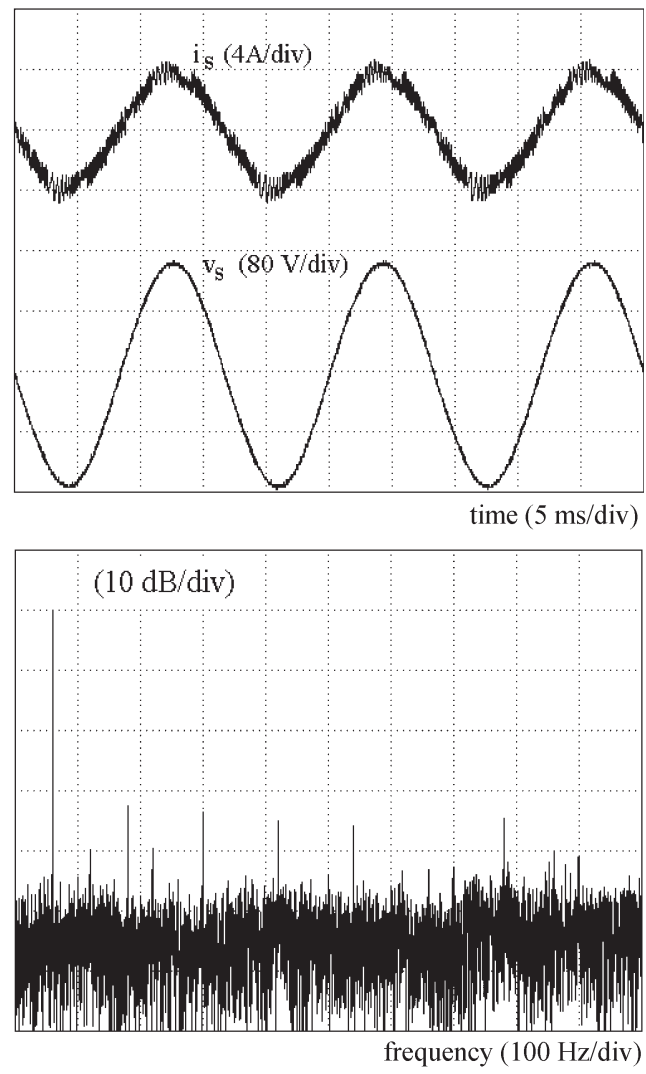

proposed control

Fig. 7. Nondistorted grid. (Top) Grid current and grid voltage. (Bottom) Grid-current spectra.

response. In the experimental setup, a simple secondorder bandpass filter, with unity gain at resonant frequency, was used.

The utility grid feeds a nonlinear load, as shown in Fig. 1. The load is composed of a series resistance $R_{s}$, used to establish the desired crest factor, a diode bridge, and a resistance $R_{o}$ in parallel with a capacitor $C_{o}$. Fig. 6 shows the load current $i_{o}$ under nondistorted grid and its spectrum.

The measured grid voltage (THD, calculated with respect to the fundamental value of the signal) is $2 \%$. The crest factor of the load current is 2.27 , with a power factor of 0.73 . The THD of the load current, considering up to the 21st-harmonic component, is $83.92 \%$.

\section{B. Test Results}

To evaluate the proposed controller, a performance comparison with a reference controller, described in [8], is carried out. This reference controller has been described in detail in Section II. Fig. 7 shows the time waveforms of the experimental grid current and voltage when the active filter is governed by the reference and by the proposed control. As a prominent feature and due to the inherent characteristics of the bandpass filter, there is no noticeable phase deviation between the grid voltage $v_{s}$ and the grid current $i_{s}$ when using both controls. Fig. 7 also shows the measured spectra of the grid current with both controllers. With the proposed controller, the grid-current THD drops to $5.10 \%$, providing a high reduction in the $3 \mathrm{rd}$, 5th, 7th, 9th, and 11th harmonics with respect to the load current (see Fig. 6). When using the reference control, the grid current THD drops to $5.29 \%$.

In practical applications, the grid-voltage waveform is normally distorted. To compare the performance of both controllers in such a situation, a distorted grid voltage with an $8.92 \%$ THD has been employed. Moreover, the measured load-current THD is $60.34 \%$. In that case, the reference current $i_{s}^{*}$ has a significant harmonic content in the reference controller.

Fig. 8 shows the experimental grid-current waveforms using both the reference control and the proposed control. In this case, the reference control presents an unacceptable grid-currentharmonic distortion coming from the grid voltage, which is replicated. As can be seen, the proposed control maintains the harmonic-rejection capability also when the grid voltage is distorted. The nearly sinusoidal grid current $i_{s}$, obtained with the proposed control, shows that most of the load current harmonics have been compensated for successfully, see Fig. 8. The grid-current THD is $12.15 \%$ when testing the reference control but it drops to only $6.11 \%$ with our proposal.

Fig. 9 shows again the grid-current spectra but now with a larger frequency axis (up to $30 \mathrm{kHz}$ ). As can be seen, both high-frequency spectra are very similar. Thus, the proposed controller achieves similar performance in these frequency range but with the benefit of simple-control implementation.

The dynamic performance of both controllers under stepload changes was evaluated and compared. Fig. 10 shows the transient response of the grid current and the capacitor voltage for the proposed controller. The load is changed from 


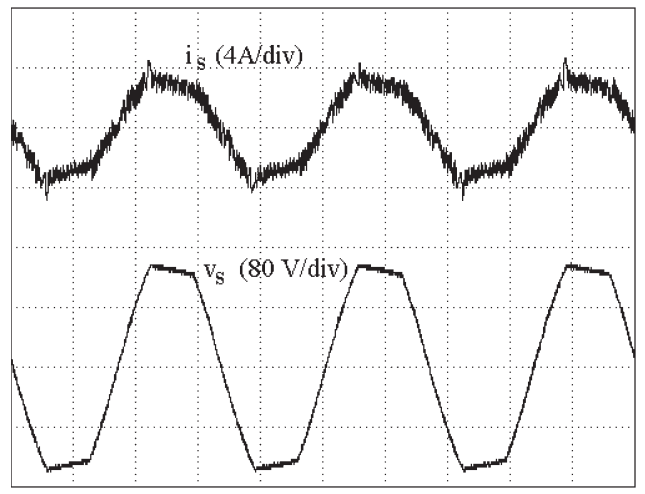

time $(5 \mathrm{~ms} / \mathrm{div})$

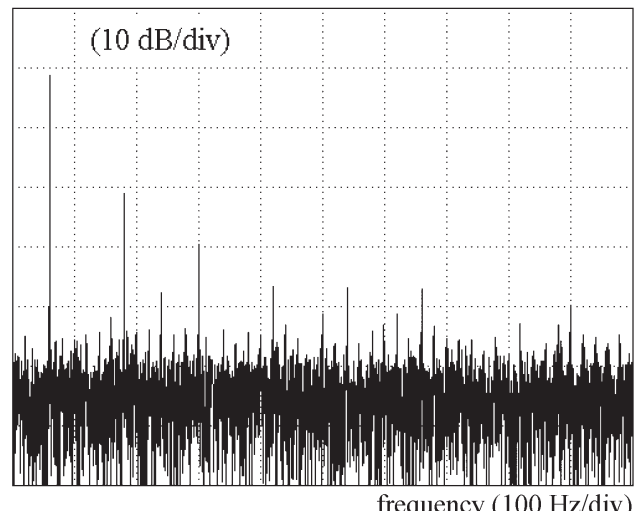

reference control
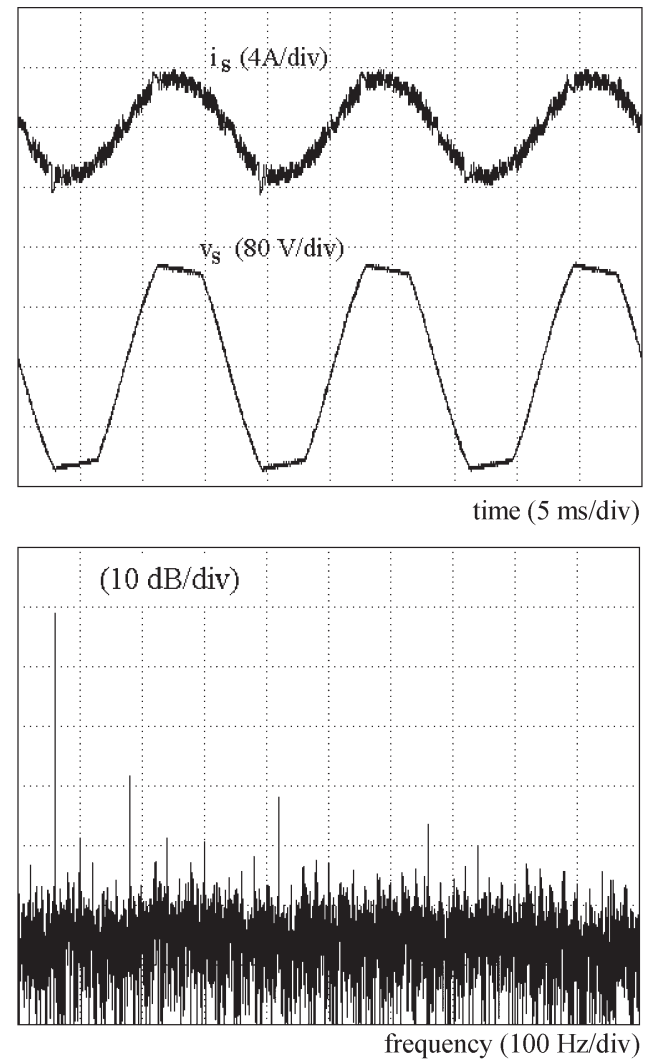

proposed control

Fig. 8. Distorted grid. (Top) Grid current and grid voltage (top). (Bottom) Grid-current spectra.
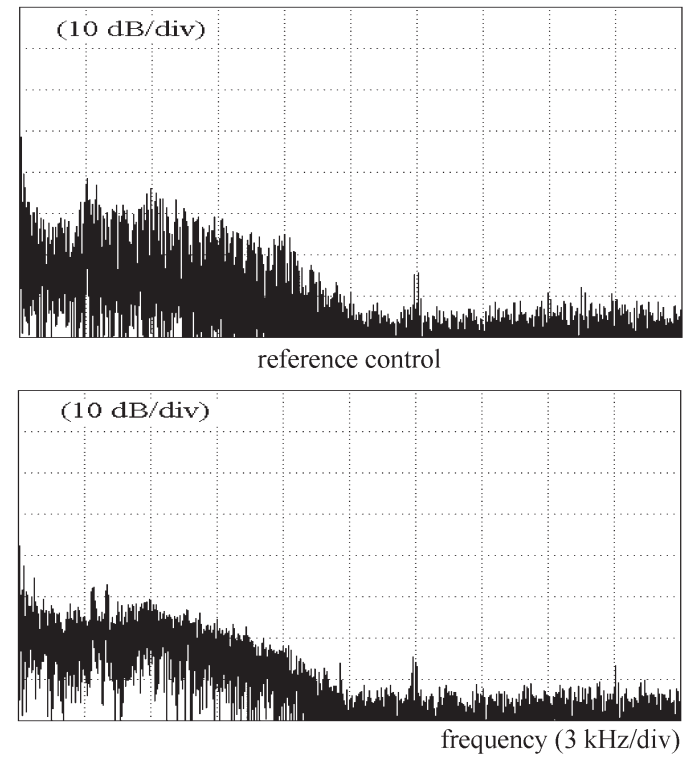

proposed control

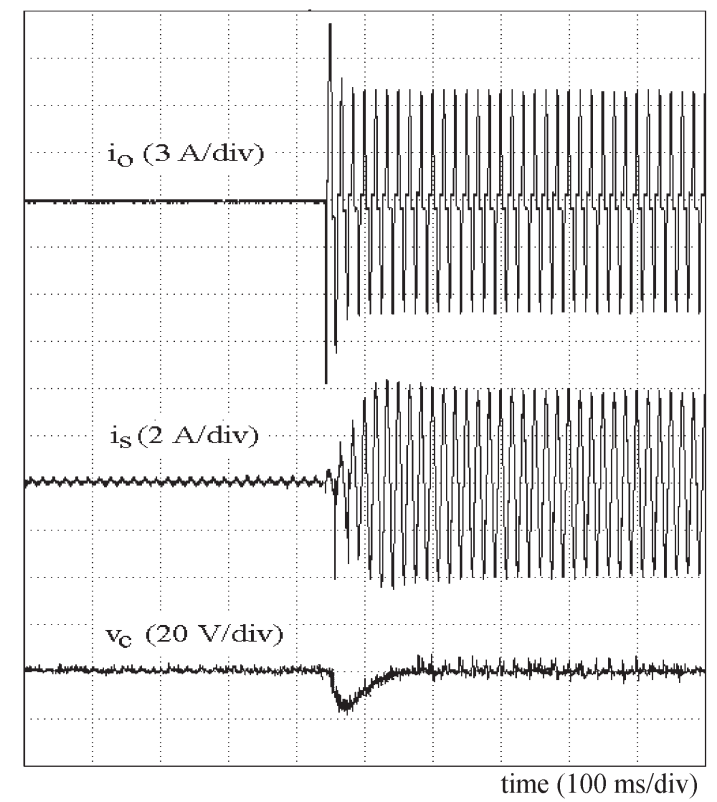

Fig. 10. Response to load-step change from $0 \%$ to $100 \%$ using the proposed control.

\section{Discussion}

The proposed controller is a simple low-cost analog solution for single-phase APF systems. The analog multiplier used in the conventional control is substituted by a multiplexer and a bandpass filter. Moreover, the sensing of the grid voltage is no longer required. The performance of the APF system with the 
proposed control is improved in relation to the performance of the conventional control. In fact, the THD of the grid current is small, and it has low sensitivity to grid-voltage THD variations. This interesting property could be attributed to the low bandwidth of the bandpass filter which rejects all the unwanted harmonics.

The proposed control is particularly suitable for environments in which the grid frequency presents small deviations from its nominal value. Variations smaller than $2 \%$ of the nominal grid frequency (which is the normal situation in large grid systems [37]) does not deteriorate significantly the performance of the proposed APF system. In fact, a displacement power factor of 0.99 is measured when the frequency has a positive $2 \%$ deviation. Moreover, the grid-current THD is unaffected in this situation.

In environments in which high deviation in the utility grid frequency is expected, the displacement power factor of the APF system could be unacceptable. The reason for this performance deterioration is that the bandpass filter operates at a frequency different from its nominal resonance frequency, and, thus, a high phase deviation between the grid voltage and current is produced.

\section{CONCLUSION}

The injection of sinusoidal current to the electrical grid is nowadays possible with the use of APFs. With QSS nonlinear controllers, these power filters provide low grid-currentharmonic content with simple-control analog implementation. This paper has been focused on the design of a QSS nonlinear controller for a single-phase APF. A complete analysis based on the sliding-mode-control theory has been given. From the analysis, a set of control-design guidelines were presented to select the gains and parameters of the control scheme. The performance characteristics of the proposed controller were evaluated experimentally and compared with the features of a reference controller. In view of these results, we can conclude that the proposed controller offers low grid-current-harmonic content with low sensitivity to grid-voltage distortion.

\section{REFERENCES}

[1] H. Akagi, "Trends in active power line conditioners," IEEE Trans. Power Electron., vol. 9, no. 3, pp. 263-268, May 1994.

[2] H. Akagi, "Active harmonic filters," Proc. IEEE, vol. 93, no. 12, pp. 21282141, Dec. 2005.

[3] M. El-Habrouk, M. K. Darwish, and P. Mehta, "A survey of active filters and reactive power compensation techniques," in Proc. IEE Conf. Power Electron. Variable Speed Drives (Conf. Publ. No. 475), 2000, pp. 7-12.

[4] M. P. Kazmierkowski and L. Malesani, "Current control techniques for three-phase voltage-source PWM converters: A survey," IEEE Trans. Ind. Electron., vol. 45, no. 5, pp. 691-703, Oct. 1998.

[5] T. C. Green and J. H. Marks, "Control techniques for active power filters," Proc. Inst. Elect. Eng.-Elect. Power Appl., vol. 152, no. 2, pp. 369-381, Mar. 2005.

[6] M. Cirrincione, M. Pucci, and G. Vitale, "A single-phase DG generation unit with shunt active power filter capability by adaptive neural filtering," IEEE Trans. Ind. Electron., vol. 55, no. 5, pp. 2093-2110, May 2008.

[7] C. Y. Hsu and H. Y. Wu, "A new single-phase active power filter with reduced energy-storage capacity," Proc. Inst. Elect. Eng.-Elect. Power Appl., vol. 143, no. 1, pp. 25-30, Jan. 1996.

[8] D. A. Torrey and A. M. A. M. Al-Zamel, "Single-phase active power filters for multiple nonlinear loads," IEEE Trans. Power Electron., vol. 10, no. 3, pp. 263-272, May 1995.
[9] F. Pottker and I. Barbi, "Power factor correction of non-linear loads employing a single phase active power filter: Control strategy, design methodology and experimentation," in Proc. IEEE PESC, St. Louis, MO, Jun. 22-27, 1997, pp. 412-417.

[10] J. C. Wu and H. L. Jou, "Simplified control method for the single-phase active power filter," Proc. Inst. Elect. Eng.-Elect. Power Appl., vol. 143, no. 3, pp. 219-224, May 1996.

[11] H. Komurcugil and O. Kukrer, "A new control strategy for single-phase shunt active power filters using a Lyapunov function," IEEE Trans. Ind. Electron., vol. 53, no. 1, pp. 305-312, Feb. 2006.

[12] G. Escobar, P. R. Martinez, and J. Leyva-Ramos, "Analog circuits to implement repetitive controllers with feedforward for harmonic compensation," IEEE Trans. Ind. Electron., vol. 55, no. 1, pp. 567-573, Feb. 2007.

[13] L. Asiminoaei, E. Aeloiza, N. Enjeti, and F. Blaabjerg, "Shunt activepower-filter topology based on parallel interleaved inverters," IEEE Trans. Ind. Electron., vol. 55, no. 3, pp. 1175-1189, Mar. 2008.

[14] K. Gulez, A. A. Adam, and H. Pastaci, "Torque ripple and EMI noise minimization in PMSM using active filter topology and field-oriented control," IEEE Trans. Ind. Electron., vol. 55, no. 1, pp. 251-257, Jan. 2008.

[15] S. Inoue, T. Shimizu, and K. Wada, "Control methods and compensation characteristics of a series active filter for a neutral conductor," IEEE Trans. Ind. Electron., vol. 54, no. 1, pp. 433-440, Feb. 2007.

[16] M. Salo and H. Tuusa, "A novel open-loop control method for a currentsource active power filter," IEEE Trans. Ind. Electron., vol. 50, no. 2, pp. 313-321, Apr. 2003.

[17] B. N. Singh, "Sliding mode control technique for indirect current controlled active filter," in Proc. IEEE Region 5, Annu. Tech. Conf., New Orleans, LA, Apr. 2003, pp. 51-58.

[18] P. Mattavelli and F. Pinhabel, "Repetitive-based control for selective harmonic compensation in active power filters," IEEE Trans. Ind. Electron., vol. 51, no. 5, pp. 118-124, Oct. 2004.

[19] R. Grino, R. Cardoner, R. Costa-Castello, and E. Fossas, "Digital repetitive control of a three-phase four-wire shunt active filter," IEEE Trans. Ind. Electron., vol. 54, no. 3, pp. 1495-1503, Jun. 2007.

[20] B.-R. Lin and Y.-C. Lee, "Three-phase power quality compensator under the unbalanced sources and nonlinear loads," IEEE Trans. Ind. Electron., vol. 51, no. 5, pp. 1009-1017, Oct. 2004.

[21] M. Cichowlas, M. Malinowski, M. P. Kazmierkowski, D. L. Sobczuk, P. Rodriguez, and J. Pou, "Active filtering function of three-phase PWM boost rectifier under different line voltage conditions," IEEE Trans. Ind. Electron., vol. 52, no. 2, pp. 410-419, Apr. 2005.

[22] T. Ohnishi and M. Hojo, "AC line voltage harmonics compensator with excessive current control," IEEE Trans. Ind. Electron., vol. 50, no. 6, pp. 1126-1133, Dec. 2003.

[23] I. Etxeberria-Otadui, A. López de Heredia, H. Gaztañaga, S. Bacha, and R. Reyero, "A single synchronous frame hybrid (SSFH) multifrequency controller for power active filters," IEEE Trans. Ind. Electron., vol. 53, no. 5, pp. 1640-1648, Oct. 2006.

[24] B. M. Han, B. Y. Bae, and S. J. Ovaska, "Reference signal generator for active power filters using improved adaptive predictive filter," IEEE Trans. Ind. Electron., vol. 52, no. 2, pp. 576-584, Apr. 2005.

[25] K. Shyu, M. Yang, Y. Chen, and Y. Lin, "Model reference adaptive control design for a shunt active-power-filter system," IEEE Trans. Ind. Electron., vol. 55, no. 1, pp. 97-106, Jan. 2008.

[26] Z. Shu, Y. Guo, and J. Lian, "Steady-state and dynamic study of active power filter with efficient FPGA-based control algorithm," IEEE Trans. Ind. Electron., vol. 55, no. 4, pp. 1527-1536, Apr. 2008.

[27] K. M. Smedley and S. Cuk, "One-cycle control of switching converters," in Proc. IEEE Power Electron. Spec. Conf., 1991, pp. 1173-1180.

[28] G. Chen and K. M. Smedley, "Steady-state and dynamic study of onecycle-controlled three-phase power-factor correction," IEEE Trans. Ind. Electron., vol. 52, no. 2, pp. 355-362, Apr. 2005.

[29] C. Quiao, T. Jin, and K. Y. Smedley, "One-cycle control of three-phase active power filter with vector operation," IEEE Trans. Ind. Electron., vol. 51, no. 2, pp. 455-463, Apr. 2004.

[30] P. Midya, P. T. Krein, and M. F. Greuel, "Sensorless current mode control-An observer-based technique for DC-DC converters," IEEE Trans. Power Electron., vol. 16, no. 4, pp. 522-526, Jul. 2001.

[31] J. Miret, L. Garcia de Vicuña, M. Castilla, J. Cruz, and M. Guerrero, "A simple sliding mode control of an active power filter," in Proc. IEEE Power Electron. Spec. Conf., 2004, pp. 1052-1056.

[32] P. Mattavelli, L. Rossetto, and G. Spiazzi, "Small-signal analysis of DC-DC converters with sliding mode control," IEEE Trans. Power Electron., vol. 12, no. 1, pp. 96-102, Jan. 1997. 
[33] H. de Battista and R. J. Mantz, "Harmonic series compensators in power systems: Their control via sliding mode," IEEE Trans. Control Syst. Technol., vol. 8, no. 6, pp. 939-947, Nov. 2000.

[34] R. A. DeCarlo, S. H. Zak, and G. P. Matthews, "Variable structure control of nonlinear multivariable systems: A tutorial," Proc. IEEE, vol. 76, no. 3, pp. 212-232, Mar. 1988.

[35] K. Mahabir, G. Verghese, J. Thottuvelil, and A. Heyman, "Linear averaged and sampled data models for large signal control of high power factor AC-DC converters," in Proc. IEEE PESC, 1990, pp. 372-381.

[36] R. Ridley, "Average small-signal analysis of the boost power factor correction circuit," in Proc. Virginia Power Electron. Center Semin., Blacksburg, VA, Sep. 1989, pp. 108-120.

[37] S. J. Ovaska and O. Vainio, "Evolutionary-programming-based optimization of reduced-rank adaptive filters for reference generation in active power filters," IEEE Trans. Ind. Electron., vol. 51, no. 4, pp. 910-916, Aug. 2004.

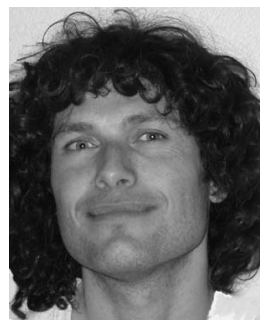

Jaume Miret (M'01) received the B.S. degree in telecommunications and the M.S. and Ph.D. degrees in electronics from the Technical University of Catalonia, Barcelona, Spain, in 1992, 1999, and 2005, respectively.

Since 1993, he has been an Assistant Professor with the Department of Electronic Engineering, Technical University of Catalonia, Vilanova i la Geltrú, Spain, where he teaches courses on digital design and circuit theory. His research interests include dc-ac converters, active power filters, and

digital control.

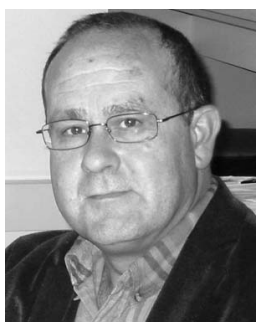

Luis García de Vicuña received the Ingeniero de Telecomunicación and Dr.Ing. degrees from the Technical University of Catalonia, Barcelona, Spain, in 1980 and 1990, respectively, and the Dr.Sci. degree from the Université Paul Sabatier, Toulouse, France, in 1992.

From 1980 to 1982, he was an Engineer with a control applications company. He is currently an Associate Professor with the Department of Electronic Engineering, Technical University of Catalonia, Vilanova i la Geltrú, Spain, where he teaches courses on power electronics. His research interests include power-electronics modeling, simulation and control, active power filtering, and high-power-factor ac/dc conversion.

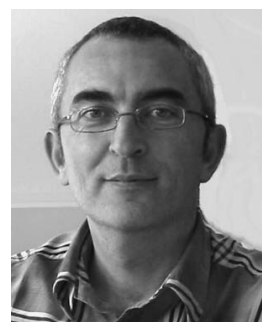

Miguel Castilla received the B.S., M.S., and Ph.D. degrees in telecommunication engineering from the Technical University of Catalonia, Barcelona, Spain, in 1988,1995 , and 1998 , respectively.

Since 2002, he has been an Associate Professor with the Department of Electronic Engineering, Technical University of Catalonia, Vilanova i la Geltrú, Spain, where he teaches courses on analog circuits and power electronics. His research interests are in the areas of power electronics, nonlinear control, and renewable-energy systems.

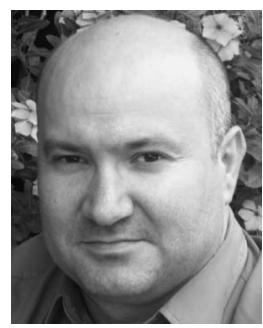

José Matas received the B.S., M.S., and Ph.D. degrees in telecommunications engineering from the Technical University of Catalonia, Barcelona, Spain, in 1988, 1996, and 2003, respectively.

From 1988 to 1990, he was an Engineer with a consumer electronics company. Since 1990, he has been an Associate Professor with the Department of Electronic Engineering, Technical University of Catalonia, Vilanova i la Geltrú, Spain. His research interests include power-factor-correction circuits, active power filters, uninterruptible power systems, distributed power systems, and nonlinear control.

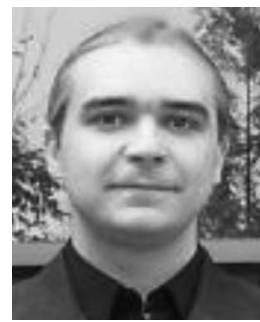

Josep M. Guerrero (S'01-M'04-SM'08) received the B.S. degree in telecommunications engineering, the M.S. degree in electronics engineering, and the $\mathrm{Ph} . \mathrm{D}$. degree in power electronics from the Technical University of Catalonia, Barcelona, Spain, in 1997 , 2000, and 2003, respectively.

$\mathrm{He}$ is an Associate Professor with the Department of Automatic Control Systems and Computer Engineering, Technical University of Catalonia, Barcelona, where he currently teaches courses on digital signal processing, field-programmable gate arrays, microprocessors, and renewable energy. Since 2004, he has been responsible for the Renewable Energy Laboratory, Escola Industrial de Barcelona, Barcelona. His research interests include photovoltaics, wind-energy conversion, uninterruptible power supplies, storage energy systems, and microgrids.

Dr. Guerrero is the Editor-in-Chief of the International Journal of Integrated Energy Systems. He is also an Associate Editor for the IEEE TRANSACTIONS ON Industrial Electronics, the IEEE TRANSACTIONS ON POWER ELECTRONICS, the International Journal of Power Electronics, and the International Journal of Industrial Electronics and Drives. 